I saw this patient in company with $\mathrm{Dr}$. Chalmers first on Friday at three o'clock, and which was seven hours after the treatment began. I saw him again in the evening, and early the following day, and once daily afterwards until Monday, when he was well, being free from all fever, and with erery function natural. In a day or two afterwards he walked out.

Since the above first case on the 7 th instant, four others have occurred. The first was in a man, who was seized at one in the morning, and who when seen for the first time eight hours after the attack had stimulants given to him, which produced or accelerated an inflammatory re-action, and be died in the evening from its effects, as was shown in the post-mortem examination by the marks of inflammation in the mucous lining of the larger curvature, and in the cardiac extremity of the stomach. The second case was of an old man, who died without any one being called to see him. The third was his widow, who was also aged, and for whom no assistance was sought until fourteen bours after the commencement of the attack, and was in a dying state when first seen. The fourth case was a young and athletic blacksmith, who was seized in the night with purging: and a few hours afterwards with vomiting and cramps, followed by some coldness and lividness of the extremities-suppression of urine, and the other signs of collapse; the pulse was distinct. He was first seen at two o'clock p.m., by Mr. Clay, of the Cholera Hospital, and Dr. Alderson, who bled him to eight ozs., gave him twelve grains of calomel with two of opium, and ordered two grains of calomel and a quarter of a grain of opium to be given every hour until the evening, when he was again bled, but with no apparent benefit. The calomel and opium were uninterruptedly continued every hour from this time, until the secretion of the liver was restored. His attack was on Tuesday last, and on Saturday he was well. Neither of these patients had any soleness of the mouth from the calomel. At the moment I am writing, this town is, I believe, without a case of the disease.

The length to which this letter has extended, forbids my yielding at this time to the intention $I$ had formed of entering into a farther consideration of the various points remaining to be noticed on the subject, and particularly in regard to the use of those misnamed auxiliary means, which I fear have been too freely and too frequently conjoined with the treatment by calomel, and too fata'ly obviated its effects.

I am, Sir, respectfully, \&c. Joseph Ayre, M. D.

Hull, April 23, 1832.
CONTRIBLTIONS TO PATHOLOGY.

No. I.

By John Alexander, M.D., one of the Medical Officers to the General Ditpensary for Children, Manchester.

\section{CASE OF INTLAMMATION OF THE} SPINAL CHORD.

December 16, 1831. Friday. I have this day been desired to visit Mrs. Wanlon, a publican's wife, ætat. 26 , of stout frame, though low stature, residing in George Lei $h$ Street, who states the following particulars. Subsequent to her third confinement, which took place fourteen months ago, she had enjoyed an uninterrupted state of good health until Sunday last, when she was attacked with considerable uneasiness in the loins, which gradually, on the Monday and Tuesday, became more and more severe. On Wednesday her usual medical attendant was sent for, and ordered four-and-twenty leeches to be applied to the part complained of, anodyne fomentations to be frequently used, and various purgatives to be administered.

This morning (Friday) her symptoms are-intolerable suffering referred to the site of the third, fourth, and fifth Jumbar vertebræ, extending laterally about a hand's breadth. On examining the part complained of, there is no decided increase of pain on pressure, unusual heat, tumefaction, discoloration, or, in a word, any deviation from a healthy appearance of the loins. The mind is anxious, and countenance flushed from suffering. Pulse 125, rather weak, and ill bearing the digical pressure; tongue whitish ; bowels obstinutely constipated, not having been relieved, although calomel and colocynth pirls, with infusion of senna, castor oil, and tincture of rhubarb, have been, during yesterday and this morning, successively administered; urine scanty, but made without difficulty.

We have prescribed a repetition of the leeches, followed by the application of a large blister, and two drops of the croton ail every two hours, until the bowels shall be aeted upon.

Ten p.m. This evening tre find our patient much easier. The leeches bled freely, and the blister is now rising. The pills have been lollowed by three dark offensive motions. Nore urine made. We have given her an anodyne containing sixty drops of laudanum, in order to induce some sleep, which she much longs for.

17. Her night has been tranquil, but today Mrs. Wanlon's case presents a melaneholy feature-that of complete paraplegia. 
The lumbar pain has entirely subsided, but her command over the lower half of the body is wholly gone, being unable to move either leg, to command the retention of her faces, or to evacuate the contents of the bladder. She appears better in spirits, the pulse being 100, tongue moist, and some appetite mentioned. We have dressed the blister with savine ointment, and directed the urine to be drawn off in the evening.

13. Nuch as yesterday, but weaker; a larger caustic issue has been placed on each side of the lumbar vertebræ; opiate repeated.

20. Not the slightest return of 'command over the limbs, which, though so powerless, have a temperature equal to that of any other part of the body. The alvine dejections are frequent and offensive. Catheter still requisite; pulse 125 , and weak. We have ordered her decoctions of bark with nitric acid three times a day, and ber dranght to be doubled in strength in order to secure sleep, and to quiet the incessant action of the bowels.

2.4. The slough on the site of the issues is considerable, and the separation almost effected. but there does not appear the slightest amelioration in the symptoms. Indeed the woman's strength is rapidly giving way. We have ordered a free use of wine, the decoction continued, and an addition of twenty-five minims of tr. opii to her draught, as her last wight was restless, and much disturbed by startings, dreams, \&c.

25. Slough separated; pulse 140. Says she feels much weaker; has slept prettv well the last night, although still observed to start and twitch during ber artificial slumber.

26. Y esterday morning a slight but troublesome cough was observed to annoy her, and has continued since to do so ; it is unattended with expectoration. Says she is perfectly free from pain; has taken a bottle of port-wine during the last twenty-four hours, and complains chiefly of a sense of sinking; pulse 148 , extremely feeble; speech almost inarticulate; abdomen become tympanitic; fieces and urine now loth passed involuntarily.

27. Mrs. Wanlon was taken in the evening with difficulty of breathing, and was soon relieved from further suffering.

The above notes are extracted from $\mathrm{my}$ sase book. 'Three days after decease, with great difficulty, leave to institute an inspection was obtained; for the following pariculars of which, owing to unavoidable absence, I am indebted to Dr. Stepbens, a talented and indefatigable cultivator of pathology, and lecturer upon anatomy in Mauchester.

\section{Post-mortem Eramination.}

"The body was well proportioned and but little emaciated. There were two eschars opposite the lateral parts of the lumbar rertebra, about the size of a crown each, evidently intentionally produced.

An incision was made from the middle of the back part of the neck to the os coccygis, and then the museles were dissected back from each side of the spinous and transverse processes and arches of the vertebræ. In doing this, about the 9 th or 10 th dorsal vertebra, or perhaps a little higher, but pre. cisely between the scapula, we opened into a small abscess on each side of the vertebra, lying close up to the vertebral column, and accompanied by slight caries of the walling vertebra. The pus contained in these abscesses was what is termed laudable, and amounted to near four ounces in quantity. The vertebral canal was then laid open to its whole extent. The theca vertebralis, for about four inches between the sboulder blades, and corresponding to the caries and abscesses, was rough, covered with lymph and pus, and greatly inflamed. On slitting up the theca we found it of a beautiful pink colour in its inner face, corresponding to the diseased external part; its remaining portion, both internal and external, appeared quite healthy. There was not any purulent matter within the theca, but at the lower part, opposite the bulb of the spinal chord, we found about two ounces and a half of a clear limpid fluid, forcibly distending the theca.

The chord having been completely ex. posed, we now proceeded to its examina. tion, and found its vessels much more tinged than is natural to them. This vascular infiltration was particularly remarked opposite the ninth and tenth dorsal vertebra, corresponding to the inflamed portion of the theca before alluded to, aid here there was an effusion of coagulated lymph (a thin layer, about the diameter of a shil. ling) on the medulla, under the arachnoid. There was observed also a patch of smaller size on the bulb of the chord.

On very particular inquiry from the family, it was elicited, that Mrs. Wanlon had suf. fered occasionally for months past, from pain in the back between the shoulders, and was in the habit of requesting a friend to forcibly rub the part complained of, which always relieved her; but during this last illness she referred all her pain to the lumbar region. Dr. Alexander repeatedly examined the spinal column, and could not detect any pain on pressure, or fluctuation in any part of the back; and I can testily that the dead body presented no outward signs of abscess or disease corresponding with that particular part between the shoul- 
ders, which I feel disposed to consider the' pressure be operating within the skull,primary seat of the disease under which she on the spinal column, or within the dedied."

\section{Remarks.}

Spinal affections, although much has been written, and undoubtedly well written, upon them, still constitute a terra incognita in the great chart of medical science; nor is this fact, although lamentable, dificult to be explained. The nerrous system generally, although performing the most vital part in the organization of man, exercises its functions in a manner not cognizable to the senses; and the important operations of that system are, therefore, only darkly viewed through the effects which we presume to be consequent upon them.

The case above related is submitted to perusal, not from its presenting any peculiar novelty of feature, but from its embracing a few topics, the brief allusion to which can scarcely prove uninteresting.

The first point to be mentioned, is the concomitant existence of the two abscesses and spinal disease in the dorsal region. From the circumstance of uneasiness having long existed in that part; from the presence of well-concocted pus in the abscesses; from the reported appearance of the spinal membranes, and caries of the vertebra; it is clear, that this joint affection, although overlooked by myself, was of no recent origin. Taking this for granted, were the abscesses productive of the spinal disease, or was the latter the cause of the abscesses? The question is an interesting one. That the spinal affection was the primary complaint although unable to prove, 1 am inclined to believe, from the following circumstances. The dorsal muscles do not present a usual site for common inflammation and its consequences; and had they been such in this case, great length of time would not have elapsed without the latter producing mor striking evidence of its existence. Again, the presence of an abscess on each side of the spinal column can more readily be accounted for on the explanation of their cause originating in one common centre, than on the more improbuble supposition, that two symmetrical abscesses should spontaneously arise; and, lastly, on this point, we find in a lower, lumbar, region (the seat of the poor woman's more recent suftering) a similar morbid state of the medulla spinalis had arisen.

$d s$ in most such instances of disease, obstinate costiveness was an early, and paralysis of the natural functions a later, symptom, there is, perhaps, scarcely a tyro in the practice of medicine to be found who has not observed the remarkible difference of effects induced by slight and considerable pressure on the nervous mass, whether that

No. 452. licate theca of an individual nerve. Yet the most experienced in the Hippocratic art remain stationary upon the same step of inquiry's threshold, and fail, however desirous or indefatigable, of discovering the rationale of this interesting fact in pathological science.

Had the case assumed a more chronic character, and the inflammatory symptoms abated-in other words, had it been a less severe one, the strychnine should have been employed according to the plan recommended by my friend Dr. James Bardsley (see "Hospital Faets and Observations"), to whom I conceive the profession and mankind are indebted for his practical monogragh on the employment of that singular medicine. But to return.

In the above report of post-mortem appearances, it is stated, that a thin layer of coagulated lymph was obserfed under the arachnoid membrane of the spinal marrow. Now as anatomical ingenuity has failed to detect any vessels, however minute, in that delicate tissue, I am inclined to consider that lymph to have been chielly produced by inflammation of the pia mater and the spinal medulla, the sources also of the limpid effusion within the theca. This point, however (as possessing little practical import), would not have been alluded to, but the peculiar and respected opinions of Ollivier and Ribes on Inflammation of the spinal membranes, particularly of the arachnoid, bestow upon it a reflected interest.

In conclusion, it is an opinion of Janson, as quoted by Ollivier, that paralysis of the limbs, without being attended by contraction of them, depends on inflammation of the nervous structure alone, whilst the tonic contraction of the extremities, frequently seen, is to be atributed to the complication of inflummation of the membranes along with that of the spinal medulla. Now in Mrs. Wanlon's case, the meningeal inflammation was very considerable, and that of the medulla less so ; yet tonic regidity never once presented itself either in the earlier or later stages of the paraplegic affection.

\section{DR. ADDISON.}

To the Editor of Tü Lixcet.

SiR,-Permit me to say a few words in reply to some remarks published in the last number of 'I'He Laxcer, under the signature of Guyensis, containing insinuations agdinst one of the physicians of Guy's Hospital, which I think, Sir, I can prove to hare no 